\title{
LIFE CYCLE COSTING IN CONSTRUCTION: CURRENT TRENDS AND EMERGING DIRECTIONS
}

\author{
Anupa Manewa ${ }^{1}$, Mohan Siriwardena ${ }^{2}$ and Christaline Wijekoon ${ }^{3}$
}

\begin{abstract}
The current construction climate in the UK is moving forward with a much greater attention on cost certainty, sustainability and adoption of innovative technologies. The UK Construction Strategy 2025 provides a clear direction towards achieving such goals by 2025. Life Cycle Costing (LCC) is one of successful techniques for identifying the total cost of ownership in construction assets. Even though the technique has 50 years of history, the application and the diffusion of the technique within the construction domain is comparatively limited. Therefore, this study aims to investigate the evolution and current status of LCC within construction context through Bibliometric Analysis of journal publications indexed in Web of Science database (1970-2020). A series of Contents Analyses was performed and visualisation maps were generated via VOSviewer. The findings proved that LCC has been absorbed into construction in late 90's and there is a continuous rise in the global uptake from 2013 onwards. With limited budgets and growing demand for sustainability, an integrated methodology linking LCC, Life Cycle Assessment and Performance optimisation is apparently the way forward for $L C C$.
\end{abstract}

Keywords: Life Cycle Costing; Construction; Bibliometric Analysis; New Directions.

\section{INTRODUCTION}

The UK Government's strategic vision, 'Construction 2025' (Her Majesty's Government, 2013) emphasised the need for all construction companies to strive to meet the reduction of 'project time by 50\%'; 'LCC by 33\%' and 'emissions by 50\%' by 2025 . LCC has gained a positive momentum within the UK construction industry with the introduction of the abovementioned targets. LCC is defined as the 'cost of an asset, or its parts throughout its life cycle, while fulfilling the performance requirements' (BS ISO 15686-5, 2017). The appropriateness of LCC in economic evaluation has been acknowledged within the literature. Cole and Sterner (2000) argue that the notion of LCC is generally recognised as a valuable approach for comparing alternative building designs, thereby enabling operational cost benefits to be evaluated against any initial cost increases. However, barriers have been attributed to the relatively low adoption rate of LCC, in spite of the number of advantages of the method. Lack of data, awareness of clients, methodology and standardised practices in relation to LCC have hampered quantity surveyors in its limited use. Even though the lack of standardisation of data

\footnotetext{
${ }^{1}$ School of Civil Engineering and Built Environment, Liverpool John Moores University, UK, R.M.Manewa@ljmu.ac.uk

${ }^{2}$ School of Civil Engineering and Built Environment, Liverpool John Moores University, UK, M.L.Siriwardena@1jmu.ac.uk

${ }^{3}$ School of Civil Engineering and Built Environment, Liverpool John Moores University, UK, K.A.Wijekoon@1jmu.ac.uk
} 
from various companies is at the core of the issue, ISO 15686 standard exists for sustainability data for use in construction life cycle cost analysis. However, the users either do not follow the standard or feel that does not fully encompass the requirements to make full use of LCC.

Even though the technique LCC had featured in construction education over last 50 years, its application is seemingly very limited. Therefore this study aims to investigate the current trends and emerging directions of LCC.

\section{LITERATURE REVIEW}

\subsection{Life CyCle COSTING IN CONSTRUCTION}

Life Cycle Costing (LCC) is a technique that is now perceived as a "driver" for construction change. It determines the total expenditure of a project by measuring and analysing the construction, maintenance and operational elements of an asset during the asset's through life (Dell' Isola and Kirk, 2003). LCC is mainly perceived in literature to predict cash flows and to provide an option appraisal, whilst allowing for the monitoring of costs and calculations of predicted future operational costs to an asset (Kelly and Hunter, 2009). The process involves the development of a plan, selection of LCC model, implementation of LCC model, recording and reviewing the results (Stanford University, 2005). LCC is a branch of Whole Life Costing (WLC) where WLC is defined as a systematic consideration of all relevant costs and revenues associated with the acquisition of an asset over a period of analysis as defined in the agreed scope (BS ISO 15686, 2017).

The current construction climate is in need of a robust methodology that would analyse the total cost of ownership of construction assets. Schneiderova-Heralova (2017) argues that the nature of construction industry itself is to aim for a lower acquisition cost. In a way, LCC could help to overcome this issue, with its perceived ability to enable a long-term assessment into the associated options to a building (Higham et al, 2015). In this respect, LCC allows better financial decisions to be made by considering all the relevant costs of an asset (Kelly and Hunter, 2009). Hence LCC is becoming a more dominant term within the current construction context (Kehily and Underwood, 2017). However, Bescherer (2005) and Kirkham (2014) explained that firms were only utilizing the initial cost of an asset, with very little consideration given to identifying the LCC of a project, leaving this issue to a "later date". Evidently the general pattern of costing in construction industry has primarily focused on CAPex (capital expenditure), ignoring the implications of OPex (Operational expenditure) (Ashworth et al, 2013).

The application of LCC in early stages of construction (pre-construction) will provide $70 \%-90 \%$ of cost certainty for OPex (Korpi and Ala-Risku, 2008), consequently reducing the risks (Boussabaine and Kirkham, 2008). LCC can therefore, significantly define the success of a project as it incorporates all the costs associated with the project through life. Literature further evidences the diverse applications of LCC including its ability to perform as a decision support tool (Meng and Harshaw, 2013; Gluch and Gustafsson, 2015; Minhas and Potdar, 2020), enhance sustainability (Caplehorn, 2012; Alaloul et al, 2021), and ensure value for money (Swaffield and McDonald, 2008). However, majority of research on LCC concerns tool modelling and development, and surprisingly few studies pay interest into how practitioners perceive the usefulness of the tools developed (Goh and Sun, 2016).

LCC integrates several mathematical calculations that help to identify the future costs (Flanagan et al, 2005). The methods, Annual Equivalent Cost; Net Present Value; Payback Method; Net Savings; Internal Rate of Return and Savings to Investment Ratio are quite common methods that are used within LCC (RICS, 2016). However, these calculations are 
perceived by many professionals to be complex and confusing (Kehily and Underwood, 2017), requiring expertise knowledge and have been associated with interoperability issues (Ive, 2006). The awareness of LCC is currently growing at an exponential rate. However, Olubodun et al. (2010) concluded that even though construction specialists were aware of the perceived benefits utilised by LCC, many were still reluctant to use the methodology. Fortune and Cox (2005) further stated that professionals have been slow to adopt LCC practices as a core tool for the estimations of early stage evaluations of a project. This issue of relatively low LCC implementation is noted as a current trend in literature, thereby the highlighting the need to assess the usability of LCC (Bull, 2015). Oduyemi et al. (2014) identified that lack of access and reliability of data, lack of standardisation and guidance documents and lack of awareness amongst construction clients as the key reasons for slow adoption of LCC within construction. Arguably, Perera et al. (2009) stated that although there are sufficient standards and tools available for undertaking the LCC, more attention is needed in training and understanding of the approach.

\section{RESEARCH METHOD}

Even though the demand for LCC within construction is noted, the real implementation of the technique within the practice is still limited. Literature underlines the benefits and challenges of LCC in construction however there is no clear reflection on the current status and directions of LCC. Hence, Bibliometric Analysis (Jonkers and Derrick, 2012) was used to understand the current status of the LCC and how the construction domain has acknowledged and reflected the term during the last 50 years. The journal publications on LCC available in the Web of Science database (Core Collection) have been accessed and data filtration and iteration processes were undertaken to identify the correct sample of literature. The data were analysed to understand the patterns, generate visualisation maps through Microsoft Excel 2016, Web of Science platform and VOSviewer software. The data collection was limited to Web of Science records.

\section{DATA COLLECTION, ANALYSIS AND DISCUSSIONS}

The data collection process followed a two staged approach. Firstly, the publications related to LCC within the field of Construction Engineering and Management during the last 50 years were retrieved. Secondly, the literature screening was undertaken to identify the relevant publications for this investigation.

\subsection{LITERATURE RETRIEVAL}

A list of publications available on Web of Science (Core Collection) in the area of Life Cycle Costing was retrieved on WoS platform. The term "Life cycle costing" was searched in all fields during the last 50 years $(1970-2020)$. The total of 30,564 publications were retrieved belonging to the fields of Civil Engineering, Building Construction, Material Science, Transportation, Energy, Oil and Gas, Agriculture and other industries.

\subsection{LITERATURE SCREENING PROCESS}

As the study was focused on the current status of LCC within the field of Construction Engineering and Management, the filters 'Building Construction' and 'Civil Engineering have been adopted. Due to the large number of publications the study was narrowed down to Journal articles only. This reduced the total number of journal publications to 2,912 (Civil - 2,053; Building - 859). The chronological development of publications related to LCC during the last 50 years have been plotted in Figure 1. 


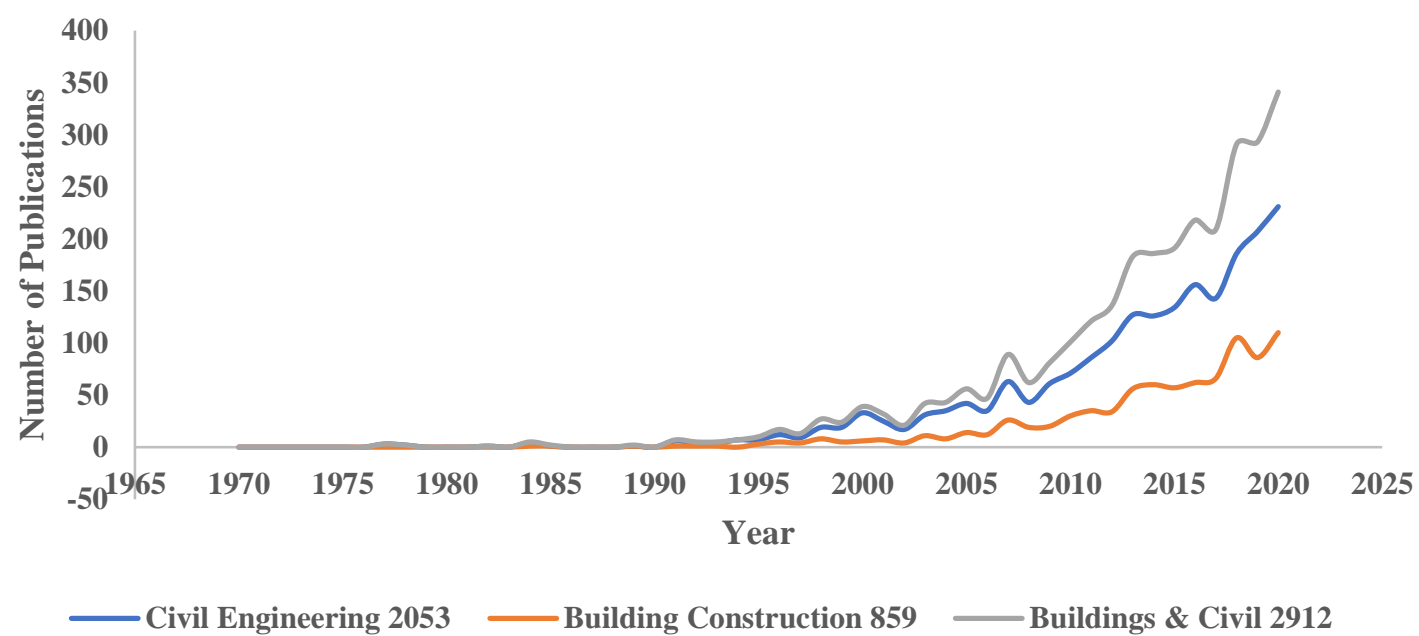

Figure 1: Chronological developments in LCC (number of journal publications)

The findings illustrate that the term "LCC" has first appeared in scientific literature in the early 70 's and then a gradual rise in number of publications from early 90's. A sharp increase was observed since 2013. With reference to Ashworth (2004, p.29) chronological development in building economics, the term "cost in use" first entered into the UK Quantity Surveying practice in early 70's and the term "LCC" has been formally introduced in early 80's.

Having studied the pattern of publications, a positive increase in the number of publications related to LCC in construction context is noted from early 90's onwards. It can be assumed that due to the increased recognition given for the built environment discipline within higher education institutions, where it shifted from a purely traditional vocational focus to a more academic focus, provided more opportunities for research in built environment. In the UK, there was an increase in the number universities as majority of Polytechnics were upgraded into University Charter (post 92 universities). This upgraded institutional recognition enabled more opportunities and resources for research including more access to Government and Industry funding.

The emergence of integrated procurement approaches such as PPPs is another influential factor for the identified positive trend in LCC. The traditional relatively short term-based silo approach has been shifted to a more life cycle phase-wise integrated (Design and Build; Public Private Partnerships, Framework Arrangements) approaches, with improved client awareness on OPex considerations. On the other hand, the Government policies (Construction 2025, Procurement Policy, 10 Point Plan) also pushed-forward the LCC implementations within UK context. A positive uptake in LCC can be expected with the introduction of International Construction Measurement Standards, which provides a global consistency in presenting the LCC data.

\subsection{Generating THE Visualisation MAPS}

To provide an in-depth analysis of the current status of LCC within the construction context, four types of visualisation maps were generated via VOSviewer. In general, each circle of the map represents a term (node), and the size of the circle and font represent the activity of the term. The larger the circle and font size, the more active the term is in the field, and vice versa. The distance between any two terms in the diagram represents the degree of association between the two terms. The shorter the distance between the two terms, the stronger the correlation and vice versa (Van Eck and Waltman, 2020). 


\subsubsection{Co-occurrence Map Based on Text Data}

The terms that are frequently apparent and their allied sub terms were identified by analysing the text data of the journal articles. This approach helps to detect any pattern of development in LCC (new terms, impactful terms etc). Total of 39,836 terms were created. However, having carefully examined the generated terms, the most relevant terms specific to LCC were further screened. As a result, a total of 216 appropriate terms were selected. In combining the criteria of "frequency of occurrence" and the "relevance" the most impactful terms are illustrated in Figure 2.

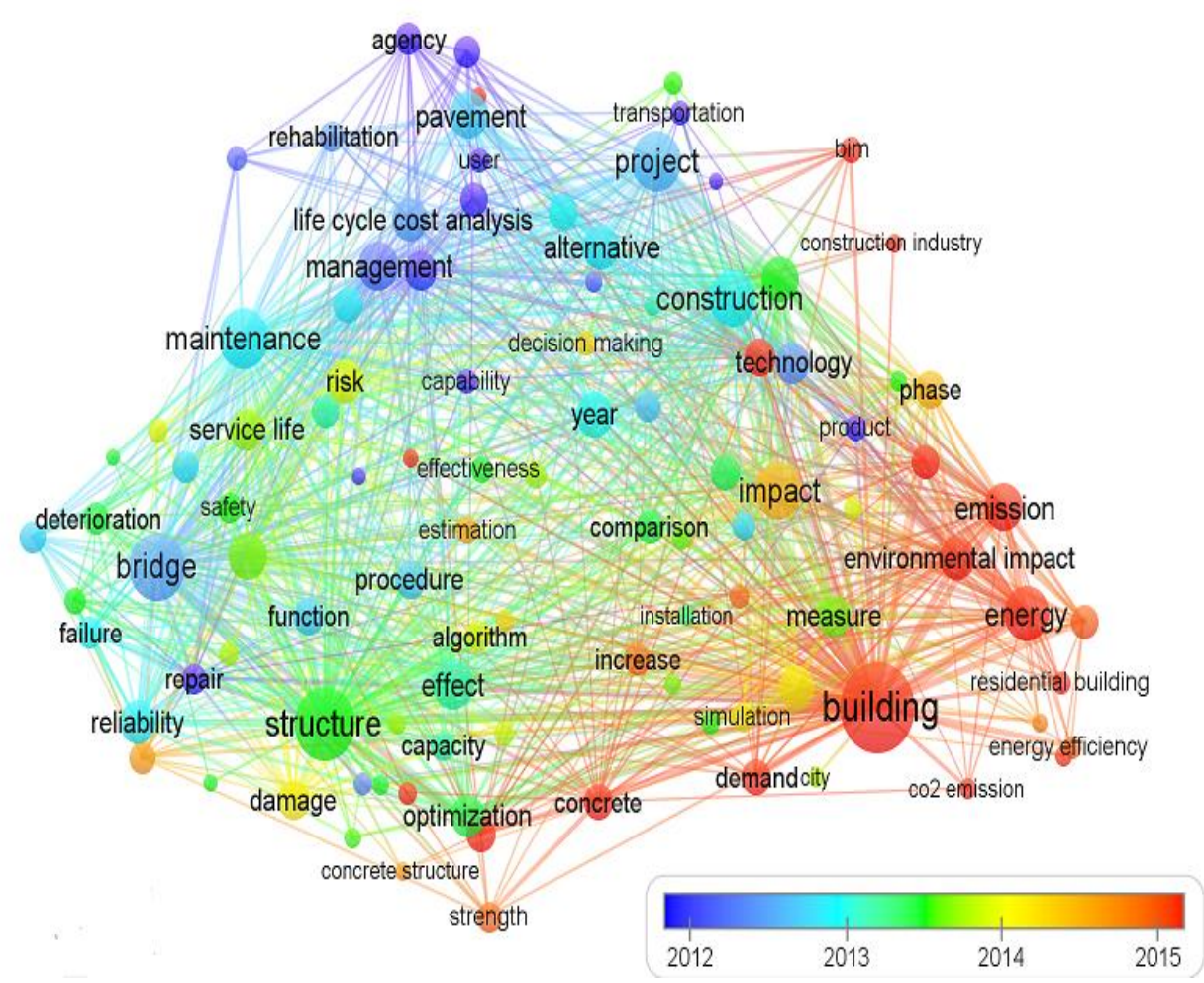

Figure 2: Co-occurrence of text data related to LCC

Civil Engineering represents an amalgamation of individual structures (roads, bridges, pavement etc) hence does not feature as a term in itself. However, the term 'Building' does appear on its own, hence is displayed as the most impactful term.

Having aligned those generated terms with the timeline $(2012$ - 2015) it is evident that the terms 'buildings', 'energy', 'technology', 'environment impact', ' $\mathrm{CO}_{2}$ emission' etc (where coloured in red) appear as the recent trend in LCC. The term 'LCC' has been isolated from the visualisation map illustrated in Figure 2 and studied further to identify the terms that are directly linked with the LCC (Figure 3).

The findings evidenced that high number of publications in relation to LCC have been produced during the period of 2012-15. The recent applications of LCC can be seen in buildings, energy, and materials sectors and some strong development in technology also noted (coloured in red). Apparently, there is a very strong connection between LCC and "risk". In a way the visualisation map provides some valid information on the LCC application in product level (buildings, roads, bridges etc), and elemental level (structures, pavement etc) and subelemental levels (steel, concrete etc). Moreover, publications are well focused on through-life applications of LCC (design, construction, maintenance, operational, rehabilitation etc) and 
also on its usability in areas of alternative analysis, cost and energy efficiency and performance optimisations.

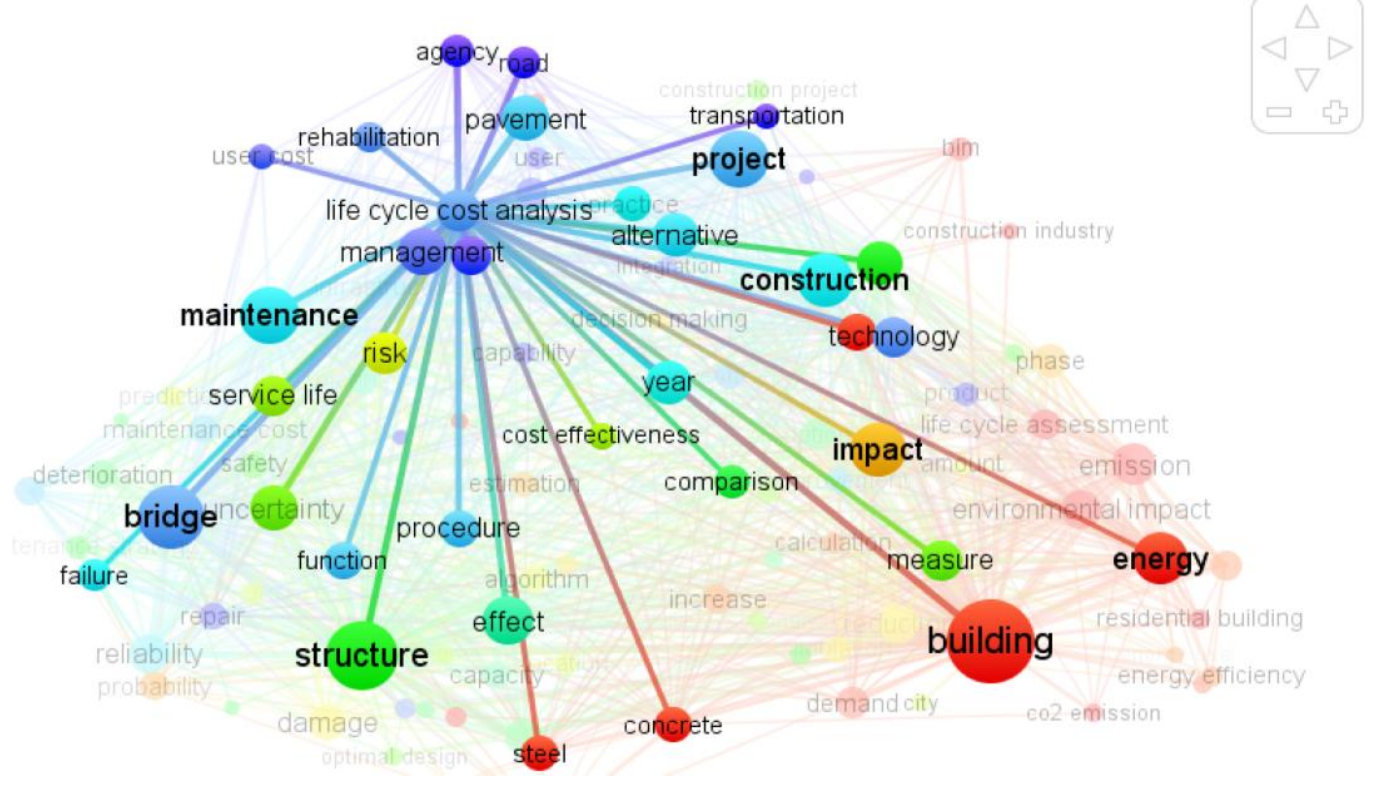

Figure 3: Terms directly connected with LCC

\subsubsection{Co-occurrences Map Based on Keywords}

The co-occurrence map of keywords was used to identify the top 10 keywords related to LCC (Figure 4). In fact the recent publications are moving towards the dimensions of sustainability, performance and integrated approaches like lifecycle assessment. The 'design', 'optimisations' and 'reliability' maintain strong links with the term LCC.

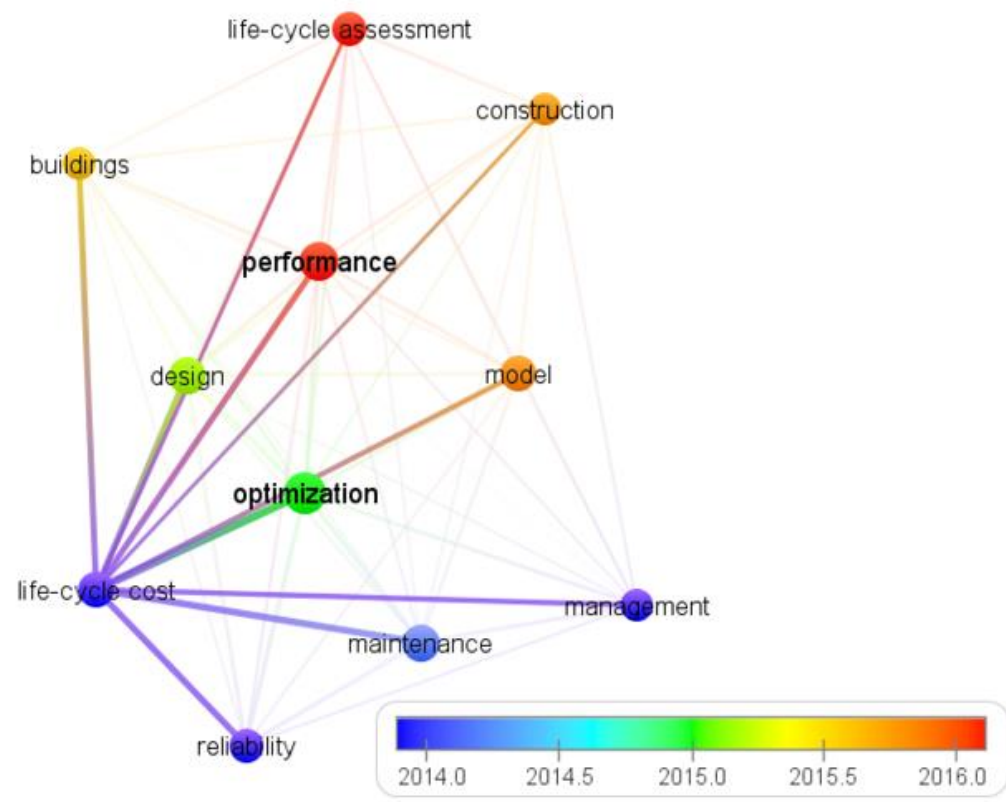

Figure 4: Co-occurrence map of keywords

This analysis also demonstrates that the term LCC has gained popularity since 2014 with its allied keywords 'maintenance', 'management' and 'reliability'. Many research were aimed at understanding the maintenance and management aspects of LCC and also the reliability of the 
technique. During 2015, the application of LCC within buildings and construction is noted and sufficient attention was given in model developments. The recent past was more focused on integration and the performance. With the limited budgets and growing demand for sustainability, an integrated methodology linking LCC, life cycle assessment and performance optimisation seems to be a recent trend in LCC.

\subsubsection{Co-occurrence Map Based on Country of Co-Authorship}

Data analysis also identified the geographical spread of the publications. The visualisation map was generated for country of co-authorship by allowing a minimum number of documents of country into 10 . Of the 82 countries, 40 met the threshold and findings are illustrated in Figure 5.

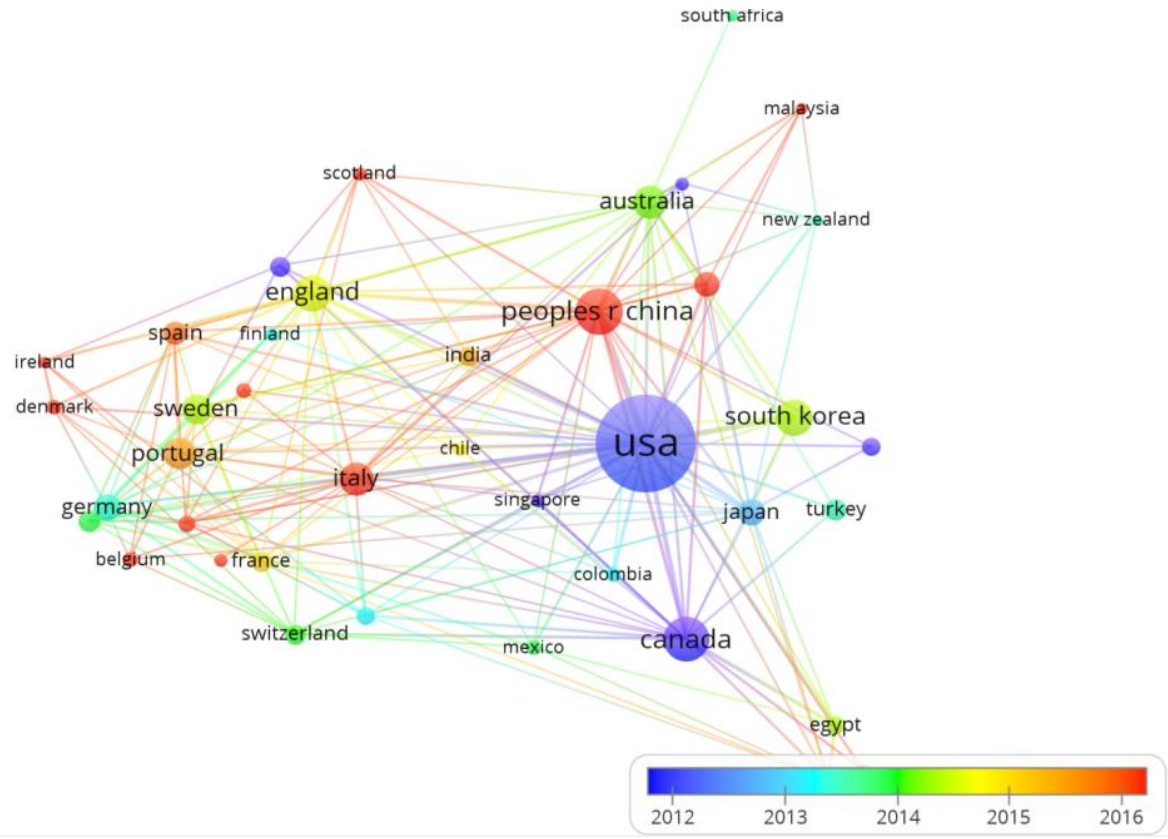

Figure 5: Country of co-authorships

Most publications appeared in the North American context (USA, Canada), followed by China and UK (England, Northern Ireland, Scotland, nothing from Wales). It was further noted there is a growing popularity of LCC in China and other EU countries (Italy, Span, Denmark, France, Belgium etc).

Being the country of origin for LCC, the USA has a recorded number of publications. In general, there is a continuous growth within North American context (including Canada). With a substantial increase in in built environment infrastructure and related higher education institutions, the People's Republic of China also produced a notable number of publications in LCC. Being a major research hub for built environment research, the UK (England, Ireland, Scotland, Wales) is placed in fourth position, and current trend in LCC is more visible in EU countries too. However, there is no clear evidence on the number of publications in other languages in relation to LCC, hence it is difficult to provide an overall conclusion in this regard.

\subsubsection{Co-occurrence Map Based on Sources}

The co-occurrences map of journals of the publications was also performed. Here minimum number of citations per source was limited into 5 as this will provide assured credibility of the publication. From a total of 229 sources (journals) 80 met the threshold, and findings are presented in Figures 6 and 7. 


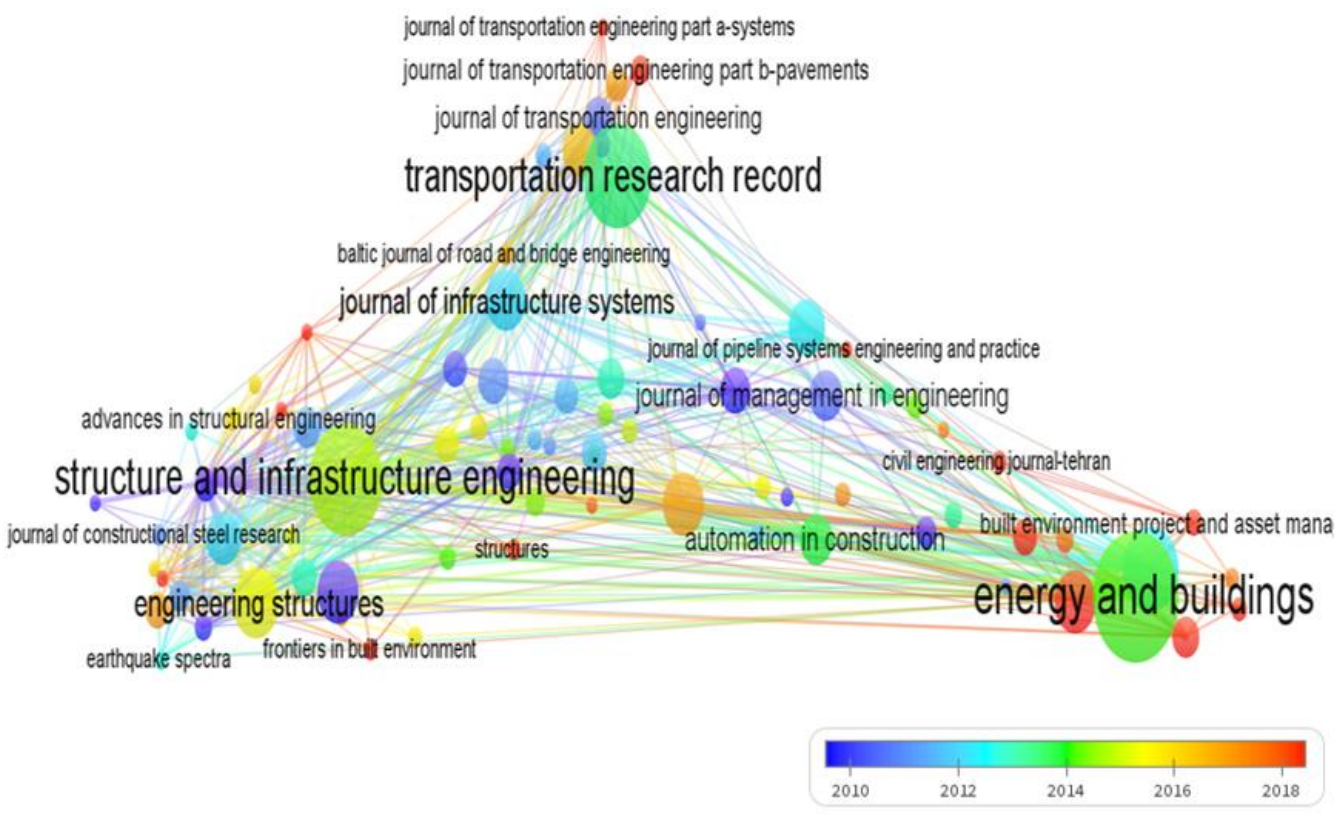

Figure 6: Co-occurrences of sources

The 80 sources were categorised under three main clusters; 'Buildings and Energy', 'Engineering and Infrastructure' and 'Transportation'. High number of publications appeared in the journals of 'Energy and Buildings' (214), 'Structure and Infrastructure Engineering' (156) and 'Transport and Research Record' (141). Majority of the recent publications (2018) appeared in the journals within the built environment disciplines. Therefore, the cluster 'Buildings and Energy' is enlarged and illustrated in Figure 7.

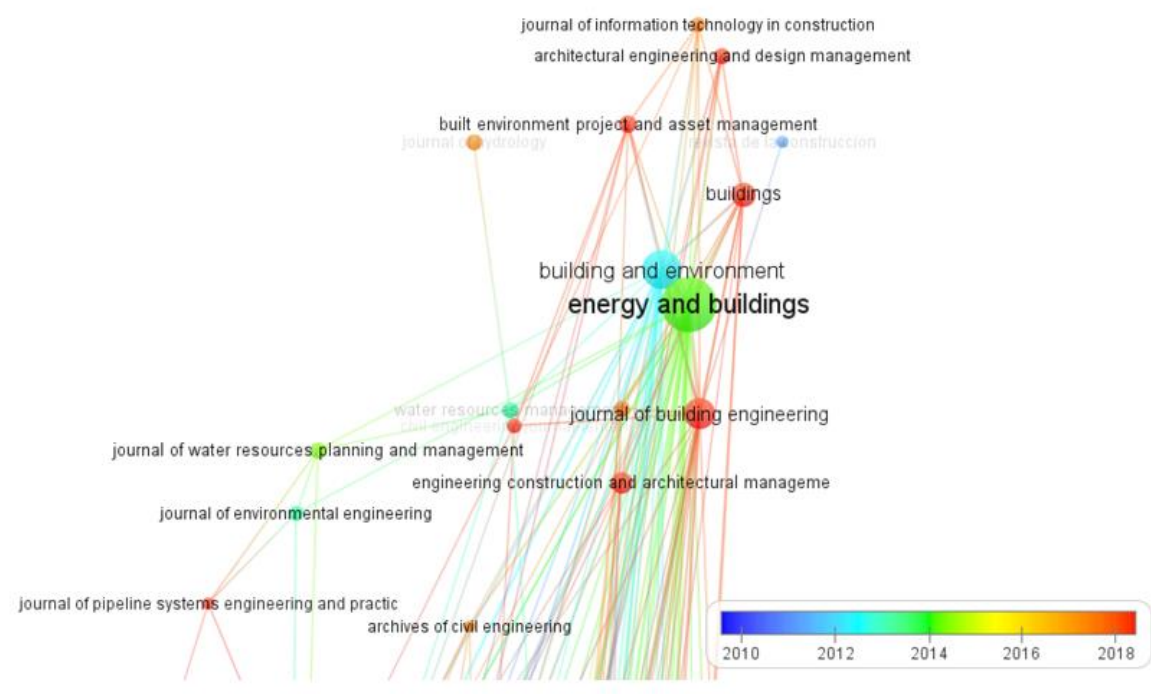

Figure 7: Sources of LCC publications within built environment discipline

Some of such journals are 'Buildings', 'Journal of Building Engineering', 'Architectural Engineering and Design Management', 'Engineering Construction and Architectural Management', 'Built Environment Project and Asset Management' entail most of the recent publications (2018 - nodes in red).

From the analysis of sources, it is evident that LCC in Civil Engineering and Buildings are still popular within Construction Engineering and Management discipline. However, the selective 
approach of Web of Science produces a curated collection of documents, and as a result some journals that are not indexed within the WoS may not have been selected, thereby omitting a large number of publications in the field.

\section{CONCLUSIONS}

The study focused on understanding the current status of LCC in construction context. Bibliometric analysis was performed by using the published materials on LCC over last 50 years. A gradual rise in number of publications since 1990, and by 2020 a sixfold increase is noted. In the UK context the Government mandate (Construction Strategy 2025) and new procurement approaches are seemingly the two of influential reasons for the underline popularity of LCC. With the introduction of International Construction Measurement Standards in 2017, which aims to provide global consistency in reporting LCC cost data, the technique gained much more attention in the global context. The findings demonstrate that there is still a significantly high focus for LCC within the construction domain. However, the attention has shifted from conventional LCC to more integrated approaches focusing on "Sustainability" including energy, zero carbon, waste management, circular economy etc. Moreover, the findings evidenced that the future direction of the LCC is more towards enhancing/optimising the performance of LCC while achieving the UN Sustainable Development Goals. Limitations of the study are acknowledged due to the fact that the data was gathered from a single database (WoS), hence further studies are needed for a more inclusive approach and analysis.

\section{REFERENCES}

Alaloul, W.S., Altaf, M., Musarat, M.A., Javed, M.F and Mosavi, A., 2021. Systematic review of life cycle assessment and life cycle cost analysis for pavement and a case study. Sustainability, 13, p. 4377.

Ashworth, A., 2004. Cost studies of buildings. $4^{\text {th }}$ ed. England: Pearson Education Limited.

Ashworth, A., Hogg, K. and Higgs, C., 2013. Willis's practice and procedure for the quantity surveyor. $13^{\text {th }} \mathrm{ed}$. Oxford: John Wiley and Sons, Ltd.

Bescherer, F., 2005. Established life cycle concepts in the business environment - Introduction and terminology, Helsinki University of Technology, Laboratory of Industrial Management report series, Report 1/2005, ISBN 951-22-7549, [Online] Available from:

http://www.tuta.hut.fi/library/raportit/teta_report/report\%20Bescherer\%20final1.pdf

Boussabaine, A. and Kirkham, R., 2008. Whole life cycle costing: risk and risk responses. John Wiley and Sons.

BS ISO 15686-5, 2017. Buildings and constructed assets - Service life planning. British Standards Institute, London.

Bull, J.W., 2015. Life cycle costing for the analysis, management and maintenance of civil engineering infrastructure, UK: Whittles Publishing.

Caplehorn, P., 2012. Whole Life Costing - A new approach. London: Routledge.

Cole, R. and Sterner, E., 2000. Reconciling theory and practice of life-cycle costing. Building Research and Information, 28(5), pp. 368-375.

Dell'Isola, A.J. and Kirk, S.J., 2003. Life cycle costing for facilities. New York: RSMeans.

Flanagan, R., Jewell, C. and Norman, G., 2005. Whole life appraisal for construction. Oxford: Blackwell Science.

Fortune, C. and Cox, O., 2005. Current practices in building project contract price forecasting in the UK. Engineering, Construction and Architectural Management, 12(5), pp. 446-457.

Gluch, P. and Gustafsson, M., 2015. Acceptance and use of LCC as a decision support tool for renovation investments. In International Conference on Construction and Real Estate Management. [Online] Available from: https://ascelibrary.org/doi/10.1061/9780784479377.095 (Accessed $15^{\text {th }}$ May 2021)

Goh, B.H. and Sun, Y., 2016. The development of life-cycle costing for buildings. Building Research and Information, 44(3), pp. 319-333.

Higham, A., Fortune, C. and James, H., 2015. Life cycle costing: Evaluating its use in UK practice. Structural Survey, 33(1), pp. 73-87. 
Her Majesty’s Government, 2013. Construction 2025 - Industrial Strategy: government and industry in partnership, London, [Online] Available from: https://www.gov.uk/government/publications/construction2025-strategy (Accessed on 20 ${ }^{\text {th }}$ May 2021).

Ive, G., 2006. Re-examining the costs and value ratios of owning and occupying buildings. Building Research and Information, 34(3), pp. 230-245.

Jonkers, K. and Derrick, G., 2012. The bibliometric bandwagon: Characteristics of bibliometric articles outside the field literature. Journal of the American Society for Information Science and Technology, 63(4), pp. 829836.

Kehily, D. and Underwood, J., 2017. Embedding life cycle costing in 5D BIM. Journal of Information Technology in Construction, 22(1), pp.145-167.

Kelly, J. and Hunter, K., 2009. Life cycle costing of sustainable design. London: RICS.

Kirkham, R., 2014. Ferry and Brandon's cost planning of buildings. John Wiley and Sons.

Korpi, E. and Ala-Risku, T., 2008. Life cycle costing: a review of published case studies. Managerial Auditing Journal, 23(3), pp. 240-261.

Minhas, M.R. and Potdar, V., 2020. Decision support systems in construction: A bibliometric analysis. Buildings, 10, p. 108.

Oduyemi, O., Okoroh, M. and Dean, A., 2014. Barriers to life cycle costing usage. In: Raiden, A. and AboagyeNimo, E. (Eds.), Proceedings 30 th Annual ARCOM Conference, 1-3 September 2014, Portsmouth, UK, Association of Researchers in Construction Management, pp. 783-92.

Olubodun, F., Kangwa, J., Oladapo, A. and Thompson, J., 2010. An appraisal of the level of application of life cycle costing within the construction industry in the UK. Structural Survey, 28(4), pp. 254-265.

Perera, O., Morton, B. and Perfrement, T., 2009. Life cycle costing in sustainable public procurement: A question of value. International Institute for Sustainable Development: A white paper from IISD.

Royal Institution of Chartered Surveyors, (2016), Guidance Note - Life Cycle Costing, [Online] Available from: https://www.rics.org/uk/upholding-professional-standards/sector-standards/construction/blackbook/lifecycle-costing/ (Accessed on 15 ${ }^{\text {th }}$ April 2021).

Schneiderova-Heralova, R., 2018. Importance of life cycle costing for construction projects. In Proceedings of the international scientific conference - Engineering for Rural Development, Jelgava, 23 ${ }^{\text {rd }}-25^{\text {th }}$ May 2018.

Stanford University, 2005. Guidelines for life cycle cost analysis, [Online] Available from: https://sustainable.stanford.edu/sites/default/files/Guidelines_for_Life_Cycle_Cost_Analysis.pdf (Accessed on 19th May 2021)

Meng, X. and Harshaw, F., 2013. The application of whole life costing in PFI/PPP projects In: Smith, S.D and Ahiaga-Dagbui, D.D (eds), Proceedings of $29^{\text {th }}$ Annual ARCOM Conference, 2-4 September 2013, Reading, UK, Association of Researchers in Construction Management, pp. 769-778.

Swaffield, L.M. and McDonald, A.M., 2008. The contractors use of life cycle costing on PFI projects, Engineering, Construction and Architectural Management, 15(2), pp. 132-148.

Van Eck, N.J. and Waltman, L., 2020. VOSviewer Manual, [Online] Available online: https://www.vosviewer.com/documentation/Manual_VOSviewer_1.6.10.pdf, Accessed on 20 ${ }^{\text {th }}$ May 2021. 